\title{
IDENTIDADES RELIGIOSAS E CONCORRENCIA NO CAMPO RELIGIOSO
}

Pablo Seman*

\section{Introdução}

O artigo oferece, entre seus múltiplos níveis, a oportunidade de colocar em discussão condições e conceitos sob os quais é pensada a questão das identidades religiosas num contexto de pluralização e concorrência no campo religioso. Para poder colocar os meus comentários a respeito, e para ampliar o patamar empírico da discussão, começarei apresentando dados sobre a situação do pentecostalismo na Argentina ${ }^{1}$. A partir desses dados colocarei, em forma condensada (e inevitavelmente geral), a necessidade de conceber as identidades num nível de singularização que atenda as condições que o próprio contraste mostra.

\section{O pentecostalismo na Argentina}

Em comparação com o comportamento pentecostal descrito por Oro (1997), o pentecostalismo argentino difere a respeito da centralidade da demonização das entidades espirituais de outros cultos nas concepções e práticas rituais, e da heterofobia que caracteriza a IURD e uma parte importante das expressões neopentecostais do Brasil.

* Pablo Seman é doutorando no PPGAS - UFRGS. Atualmente desenvolve pesquisa sobre religião em grupos populares.

1 Os dados aqui expostos emergem do trabalho de pesquisa que estou fazendo atualmente na Argentina. Atendendo ao objetivo de sublinhar e discutir algunmas das questões que sugere o artigo de Oro preferi condensar a informação empírica e tomar os riscos da especulação e do comentário. Em forma complementar tenho referido dados que remetem para a produção de outros pesquisadores cuja contribuição é indicada especificamente no texto.

Debates do NER, Porto Alegre, ano 1, n. 1, p. 62-69. Novembro de 1997. 
1 - A pregação que reconhece e torna negativo o valor das entidades espirituais dos outros cultos tem um espaço limitado em relação ao conhecido e exposto no caso brasileiro (especialmente a IURD). E isto acontece tanto nas grandes igrejas neopentecostais urbanas como nas pequenas igrejas da grande Buenos Aires. É que a composição do discurso mostra a forte presença (e ainda o prevalecimento) de tema e termos tais como a depressão, a cura, que os médicos não podem oferecer, e a necessidade de superar o vazio da alma humana. Neste sentido resulta paradigmático o discurso do pastor de uma pequena igreja pentecostal da grande Buenos Aires. Em referencia ao consumo de drogas dizia e desafiava: "agora tem gente que fala que as drogas são más. Mas o que eu lhes digo é que esse não é o problema. O problema é o homem, é o vazio da sua alma que o faz procurar qualquer coisa". A tendência é tão marcante que na comparação entre locais cariocas e "porteños" da IURD pode se observar como nos últimos pesam diferencialmente as linguagens atentas a categorias de sofrimento psicológico (e os próprios pastores reconhecem que esse tem sido um ponto onde eles mudaram o seu discurso - Moreira-Seman, 1997).

Há uma conjunção de razões para isto acontecer. Por um lado, não existe na Argentina uma cultura religiosa não-cristã e, ao mesmo tempo, tão densa e abertamente estendida quanto a que emerge com as cultos afro-brasileiros no Brasil. E não tendo um código tão amplamente conhecido, não existe a possibilidade de constituir um inimigo facilmente identificável para os fiéis. Certamente que os argentinos (nos setores sociais e culturais onde cresce o pentecostalismo) consomem e conhecem categorias decorrentes de certos serviços espirituais. Por que, então, que elas não são utilizadas? É que na produção do quadro deve, também, se considerar o fato da influência de outros sistemas de representação que são parte do estoque de recursos simbólicos com que os sujeitos definem seus problemas (e que incidem na sua consciência religiosa). A combinação da influência das categorias próprias de diversos sistemas "psi" com a difusão de um catolicismo intimista no qual dominam relações de coração humano a coração divino resulta em uma configuração que possibilita e exige outros apelos. Assim uma das igrejas neopentecostais mais importantes da cidade de

Debates do NER, Porto Alegre, ano 1, n. 1, p. 62-69. Novembro de 1997. 
Buenos Aires pratica ortodoxamente a guerra espiritual (com uma posição similar a da IURD) mas a resolve em uma doutrina da "cura interior" (que estimula a resolver os problemas dos indivíduos propondo a introspecção e a suposição de um esquema psíquico e onde se misturam o inconsciente, o subconsciente e a alma)

2 - Por outro lado, o pentecostalismo argentino não tem desenvolvido uma política agressiva contra o catolicismo que e a cultura religiosa mais fortemente implantada. Só alguns pastores próximos a geração dos pioneiros, ou influenciados por um estilo de pregação minoritário, centram o seu discurso na crítica de figuras tais como a "mariolatria" ou o caráter "romano do catolicismo".

Junto a isto é precise sublinhar que a possibilidade de demonização da prática católica é muito menor. No pior dos casos, e da perspectiva pentecostal, o catolicismo pode parecer errado ou ineficaz. Se os exus podem resignificar-se como diabos é claro que isso não pode acontecer com a Virgem de Lujan ou San Cayetano. E os constrangimentos que bloqueiam a possibilidade da hostilidade pentecostal aumentam quando se considera que muitas vezes, no senso comum, se associam catolicismo, identidade nacional e uma série de valores sociais positivos. Neste contexto, não parece incompreensível $o$ fato de que alguns dos pioneiros do neopentecostalismo tenham praticado estratégias de não confrontação e, até, de catolicidade aparente. Assim o Pastor Gimenez (de Ondas de Amor e Paz) tornava pública a sua amizade com alguns sacerdotes católicos, e o pastor Cabrera se apresentava com roupas de sacerdote católico e, no fim das reuniões massivas que convocava nos anos 70, solicitava que os assistentes se congregassem em uma igreja cristã ainda católica. (Wynarczyk e Wynarczyk, Seman, 1994).

Concorrência cordial e, ainda, a simpatia são matizes que, também, podem se observar, correspondentemente, do lado católico em relação ao pentecostalismo (além dos membros do clero e da hierarquia que não perdem a oportunidade de estigmatizar o pentecostalismo pelo que seriam o fanatismo, a fraqueza moral e o despreparo dos seus líderes). A nível dos leigos ordenados e membros de comunidades (e sem contar os carismáticos que tem tecido um nível específico de simpatias e conflitos) pode se constatar

Debates do NER, Porto Alegre, ano 1, n. 1, p. 62-69. Novembro de 1997. 
uma faixa que concebe os pentecostais como a "outra mão da evangelização", que admira o fato de "serem fervorosos e competentes para ganhar o coração das pessoas". E, mostrando que se tem uma confluência nos termos que descrevem o ideal da prática religiosa, há católicos que valorizam nos pentecostais seu poder de oração afirmando "nesse ponto eles nos ensinam".

\section{Elementos comuns e a questão da identidade}

Mas, além deste plano imediato, existem elementos que são denominadores comuns entre a situação acima descrita e a que emerge do quadro traçado por Oro (1997). Em que as situações se assemelham? Nos pontos referentes a estrutura do processo (e não nos seus conteúdos particulares). Darei conta deles nos pontos 1 e 2 . Os restantes recolhem as conseqüências que são importantes para três breves comentários sobre o problema das identidades.

1 - Em primeiro lugar, pode-se observar, nos dois casos, que o pentecostalismo se implanta em culturas locais a mercê do sucesso das operações de alinhamento dos seus marcos interpretativos. Sejam os brasileiros, que o fazem em chave de guerra com os cultos afrobrasileiros, sejam os argentinos, que o fazem tentando apresentar a versão de uma religião respeitada, o crescimento e o sucesso estando ligados a constituição de pontos de passagens que permitem a valorização pentecostal proposta por parte das diferentes populações ...

2 - Em segundo lugar, há que se registrar os movimentos paralelos que são conseqüência do anterior. A operação por meio da qual os pentecostais constituem pontos de passagem e aproximações com formas culturais preexistentes desencadeia, nos dois casos, uma permanente e recíproca referência que se complementa com uma certa ambigüidade das identidades resultantes. Os pentecostais brasileiros viram "irmãos-inimigos" dos afro-brasileiros e pentecostais, e católicos da Argentina podem convergir na definição de alguns dos seus valores e práticas.

3 - Os anteriores pontos servem para ressaltar uma questão já presente no artigo de Oro: o pentecostalisrno cresce se 
singularizando e, portanto, se pluralizando ${ }^{2}$. E isso cria um problema que é preciso explicitar para ter em conta discussões mais intensas: o pentecostalismo cresce em grupos populares mas não só entre eles; e além disso pode seduzir pessoas vinculadas com as mais variadas experiências culturais e religiosas. $\mathrm{O}$ pentecostalismo se pluraliza e os modelos de explicação do seu crescimento tem que se pluralizar ao tempo que já não podemos falar nem do "crente" ou pentecostalismo mas de crentes e pentecostalismos.

4 - O artigo de Oro aponta uma tensão que eu gostaria de colocar em evidência. $\mathrm{O}$ pentecostalismo parece se encaminhar por duas vias diferentes. De um lado, ele se soma com as forças que encantam o mundo e parece produzir um efeito de intensificação da perspectiva religiosa em geral junto ao enriquecimento de uma espécie de fundo de recursos religiosos que são explorados situacionalmente. Mas, por outra parte, o pentecostalismo parece produzir um efeito de fracionamento e diferenciação que gera a possibilidade da guerra santa, do conflito religioso e da apresentação de princípios identitários excludentes e originais.

5 - No contexto desta tensão, e da referida pluralização do pentecostalismo, a pesquisa e as análises sobre identidades religiosas afrontam um duplo perigo: afirmar dogmaticamente as identidades como se elas não passassem por múltiplos processos de ajuste contextual ou, no lado oposto, praticar uma dissolução do conceito em nome das ambigüidades e de uma possível infinitude das apropriações. A discussão para resolver essa dita tensão exigirá colocar questões que abrangem o metodológico e o teórico mas excede o espaço desta comunicação. Com certeza, um dos caminhos mais plausíveis passa pela necessidade de discutir qual é o conceito de identidade que é possível utilizar. Neste sentido as seguintes indicações de Hervieu Leger (1997) são importantes para elaborar um conceito de identidade sensível para captar as diferentes formas dos sujeitos se incluírem numa confissão, culto ou prática religiosa: "L'identité s'analyle, dans cette perspective, comme le resultat

2 Não só existem modalidades argentinas ou brasileiras, como podem dar a entender as descrições apontadas, mas também na bibliografia especializada pode-se conferir a particularidade das experiências dos jovens, das classes medias, dos grupos indígenas, etc.

Debates do NER, Porto Alegre, ano 1, n. 1, p. 62-69. Novembro de 1997. 
(toujours précaire et susceptible d'etre remis em question) d'une trajectoire d'identification qui se realise dans la durée. Ces trajectoires d'identification ne sont pas seulement des parcours de croyance. Elles impliquent egalement tout ce qui fait Ia substance du croire: des pratiques, des appartenances vécues, des façons de concevoir le monde et de s'inscrire activement dans les differentes spheres d'action qui constituent celui-ci etc. L'orientation des ces trajectoires cristallise, pour une part, les dispositions, intêréts, et aspirations des individus".

Nesse nível, que conta com a eficácia das denominações religiosas mas integra outros fatores sociais e culturais, encontra-se uma possibilidade de resolver a tensão delineada no ponto 4 . Isto é a possibilidade de distinguir tipos que no interior de uma "confissão" determinada mostrem a diferença e a especificidade de construções simbólicas e práticas que trazem o processo de mudança no campo religioso sem desconhecer os efeitos de ambigüidade que trazem os processos de re-alinhamento que os diversos grupos fazem para ocupar um espaço numa situação de concorrência e pluralização. 


\section{Referências Bibliográficas}

Hervieu-Leger D. (1997) "La transmission religieuse en modernité: élements pour la construction d'un object de recherche", Social Compass, v. 44, n 1, 131:143.

Hervieu-Leger D. (1997) "Transmission et formation des identités socio-religieuses en modernité. Essai d'analyse des trajectoires d'identification." (mimeo).

Moreira P.-Seman P. "Dios e el diablo en el pentecostalismo argentino", VI Reunião ABA (mercosul), Piriapolis, Noviembre 1997.

Oro, A. (1997), Neopentecostais e afro-brasileiros: quem vencerá esla guerra? Debates do NER, ano 1, n. 1, 1997.

Wynarczyk, (s/d) "Três evangelistas carismáiticos", Mimeo.

Wynarczyk, H.-Seman, P. (1994) "Campo Evangélico e Pentecostalismo en la Argentina", A. Frigerio (Compilador), El Pentecostalismo en la Argentina, CEAL, Buenos Aires, 29-43. 